\title{
PRIMARY PULMONARY HYPERTENSION IN CHILDHOOD
}

\author{
BY \\ J. F. FARRAR, ${ }^{*}$ R. D. K. REYE, AND DOUGLAS STUCKEY \\ From the Adolf Basser Institute of Cardiology and the Institute of Pathology, Royal Alexandra Hospital for Children, \\ Sydney, Australia \\ Received January 5, 1961
}

Despite the intensive study that has followed early discoveries, pulmonary hypertension in its various aspects continues to be a problem in clinical medicine. The means by which certain functional or structural changes occur in the lung and increase its resistance to blood flow remain obscure. It is true that these changes may be studied in histological detail at autopsy but the part that they play in the living organ is difficult to define. This is especially true of cases classified under the heading of primary pulmonary hypertension, in which traditionally are listed the cases which we know least about, and which therefore remain ætiologically indistinguishable among themselves. In the absence of a large communication between the pulmonary and systemic circulations to invite surgical repair or to produce cyanosis, the symptomatology and causes of death are different from the Eisenmenger group of pulmonary hypertension. Very high pulmonary pressures and resistances are required to produce symptoms and signs.

Primary pulmonary hypertension is listed in a special category of Wood's classification (1956), since the obliterative, vasoconstrictive, or reactive lesions according to this classification may be involved. Obliterative lesions, however, are almost always to be found, and may be produced by intimal hyperplasia of small pulmonary vessels, thrombosis, or arteritis. Thrombosis may be primary or secondary to changes that occur in the vessel wall following inflammation or high pressure. A result of the latter may be vasoconstriction, and from this may follow muscular hypertrophy in varying degree.

Primary pulmonary hypertension, as usually described, occurs predominantly in young women between the ages of twenty and forty, although cases of most ages and of both sexes have been reported. (Berthrong and Cochran, 1955; Brenner, 1935; Chapman et al., 1957; Cross and Kobayshi, 1947; Wade and Ball, 1957; Fleming, 1960; and Okuyama, 1958). The disease is about three times as common in women. It was surprising, therefore, to observe over a short period of time a number of cases of right ventricular hypertrophy in infants and children in the absence of known causes. The group under discussion occurred in later childhood, in distinction from a group of five cases in new-born children observed by ourselves, who died with right ventricular hypertrophy and right heart failure without any obvious cause, even in the lung structure.

\section{MATERIAL}

Four patients aged four to nine years were observed. In three of them the illness had a rapid course ending in death in less than one year, in keeping with the findings in the younger patients of Evans et al. (1957). Another patient fulfils the clinical criteria of primary pulmonary hypertension, but has maintained reasonable health over a period of three years. The three patients who died had presented within a pericid of two months and autopsy was performed in each of these. 


\section{Clinical Features}

The presenting symptoms were syncope on effort, cardiac pain, or dyspnœa. In two of the cases the sudden onset of symptoms had been preceded by a vague febrile illness some weeks previously and, in one of these, a similar minor illness was suffered by two other members of the same family at about the same time. Apart from this feature, there was no serious similar illness in the family histories in contrast to the cases of Coleman et al. (1959) and Fleming (1960).

The findings on physical examination in these patients with pulmonary hypertension were similar in most respects to the adult group, except that the jugular venous "a" wave was not seen so prominently, venous pressure in children being clinically more difficult to determine. There was no central cyanosis or clubbing of the fingers. Palpable right ventricular over-activity and a palpable pulmonary artery pulsation were present. Auscultation revealed an insignificant systolic murmur preceded in three patients by an early systolic click and succeeded always by a very loud pulmonary second sound. In one patient there was a pulmonary diastolic murmur. No right ventricular third heart sound was heard. In those with gross right ventricular dilation there was a systolic murmur of tricuspid regurgitation.

\section{ELECTROCARDIOGRAPHIC Findings}

The electrocardiogram in the early stages of the disease usually revealed moderate right ventricular hypertrophy only. This feature was well shown in one child (K.H.), who had cardiac pain on effort during the early stages of the disease when right ventricular hypertrophy was moderate

K.H.

K.H.

28.7 .59

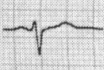

LI

L2

L3

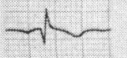

AVR

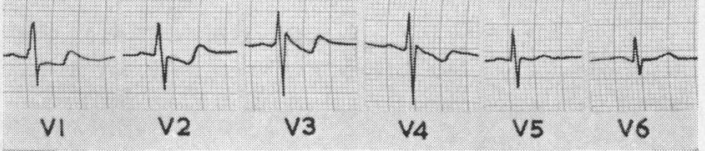

FIG. 1.-Electrocardiogram of a nine-year-old male patient suffering from primary pulmonary hypertension, taken on July 28, 1959, showing moderate right ventricular hypertrophy.

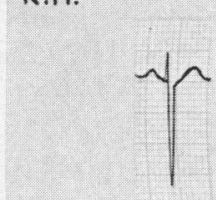

LI

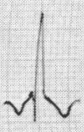

AVR

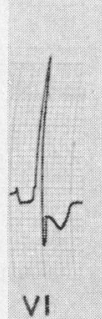

FIG. 2.-Electrocardiogram of same patient as in Fig. 1, taken on January 5, 1960, showing greater right ventricular hypertrophy.

(Fig. 1). Six months later, when right ventricular hypertrophy was severe, he did not complain of cardiac pain and had shown distinct clinical improvement (Fig. 2).

Cardiac pain in children is difficult to recognize on the history alone, and to assist in this diagnosis an exercise test was performed. Figure 3 shows a positive result of the exercise test, which was sufficient 
to provoke chest pain. The S-T segment depression in the test of August 5, 1959 confirmed the suspicion of ischæmic pain. This was abscent on September 28, after a similar exercise test.

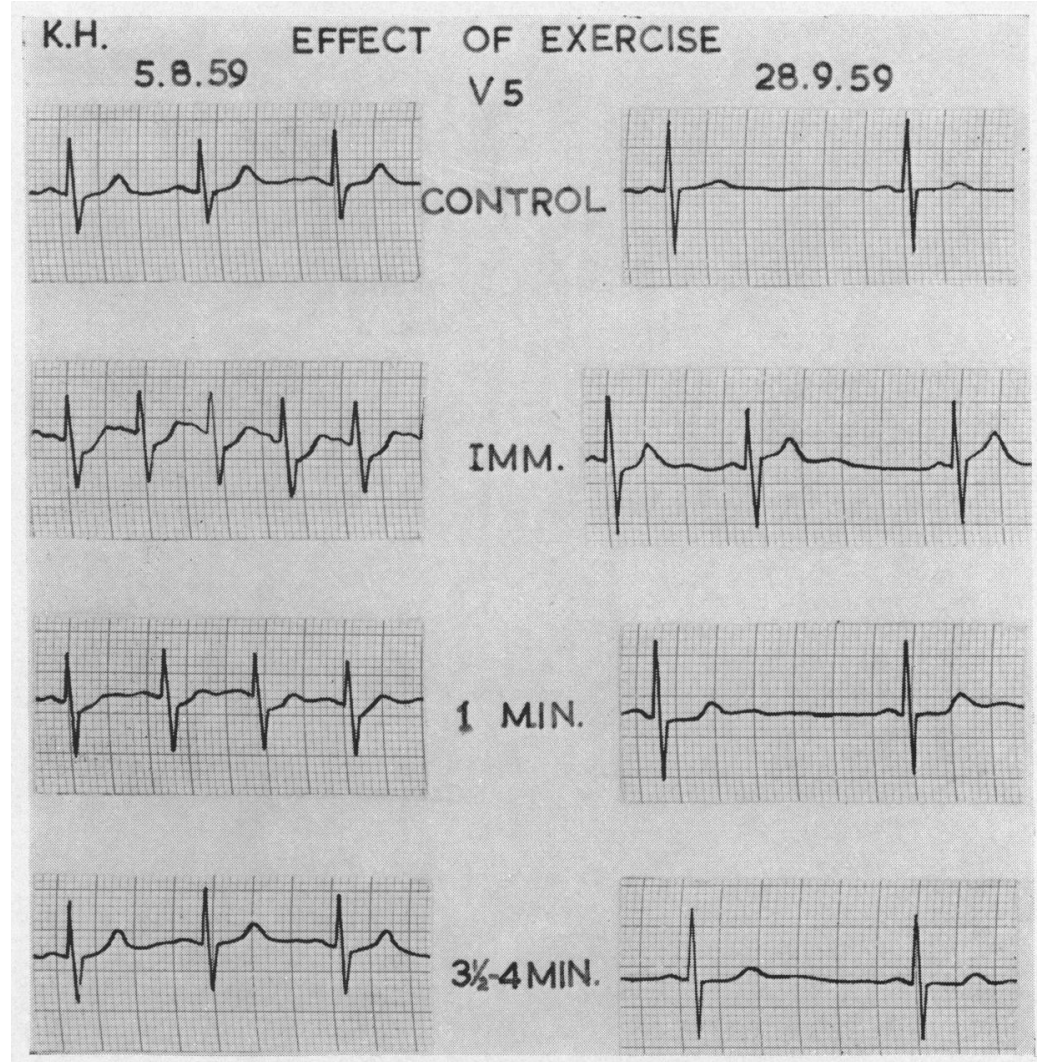

FIG. 3.-Exercise test electrocardiograms of the patient whose tracings are shown in Fig. 1 and 2 . The tracing on the left, taken at the same time as Fig. 1, shows significant S-T segment depression and tachycardia, while that on the right, taken nearer the time when Fig. 2 was taken, is within normal limits. There is no significant S-T segment depression or tachycardia.

\section{RADIOGRAPHIC FINDINGS}

X-ray appearances were similar to those usually described in adult cases of primary pulmonary hypertension, the features being slight cardiac enlargement, a large main pulmonary trunk and proximal branches, and very ischæmic peripheral lung fields. In addition, there may be obvious right atrial enlargement and an inconspicuous aorta (Fig. 4).

The ischæmia of the peripheral lung field is well demonstrated by the post-mortem pulmonary arteriogram performed by Dr. G. Beness (Fig. 5) in which comparison is made with a normal lung from a patient who had died from pneumococcal meningitis. The sudden diminution in calibre of the pulmonary arteries as they approach the periphery is well shown, and this is equally distributed throughout upper and lower zones. The larger pulmonary arteries are dilated and tortuous, resembling the picture seen in post-mortem arteriograms of the Eisenmenger reaction (Doyle et al., 1957) rather than that seen in mitral stenosis, where the vessels chiefly in the lower zones were narrowed internally but were not tortuous (Davies et al., 1953). Small branches arising before the block and passing distally are seen. As vessels of this size do not usually arise from large trunks, their nature was uncertain: nor was it apparent after histological examination. 


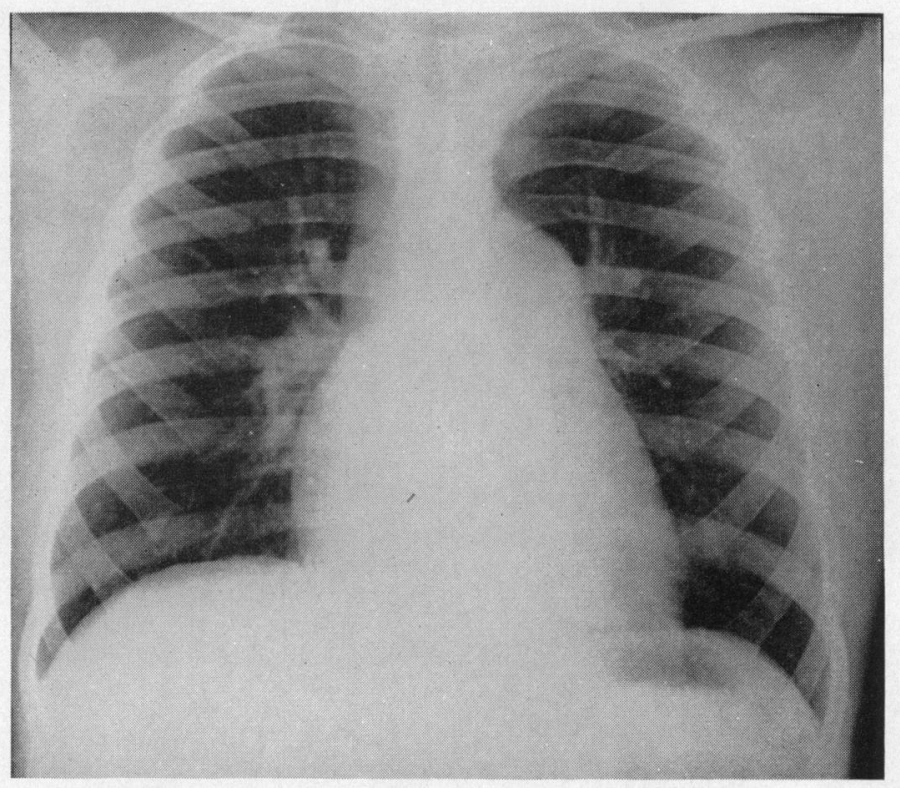

FIG. 4. - X-ray of nine-year-old male patient (Case K.H.) suffering from primary pulmonary hypertension. Notable features are enlarged main pulmonary trunk and ischæmic peripheral lung fields.

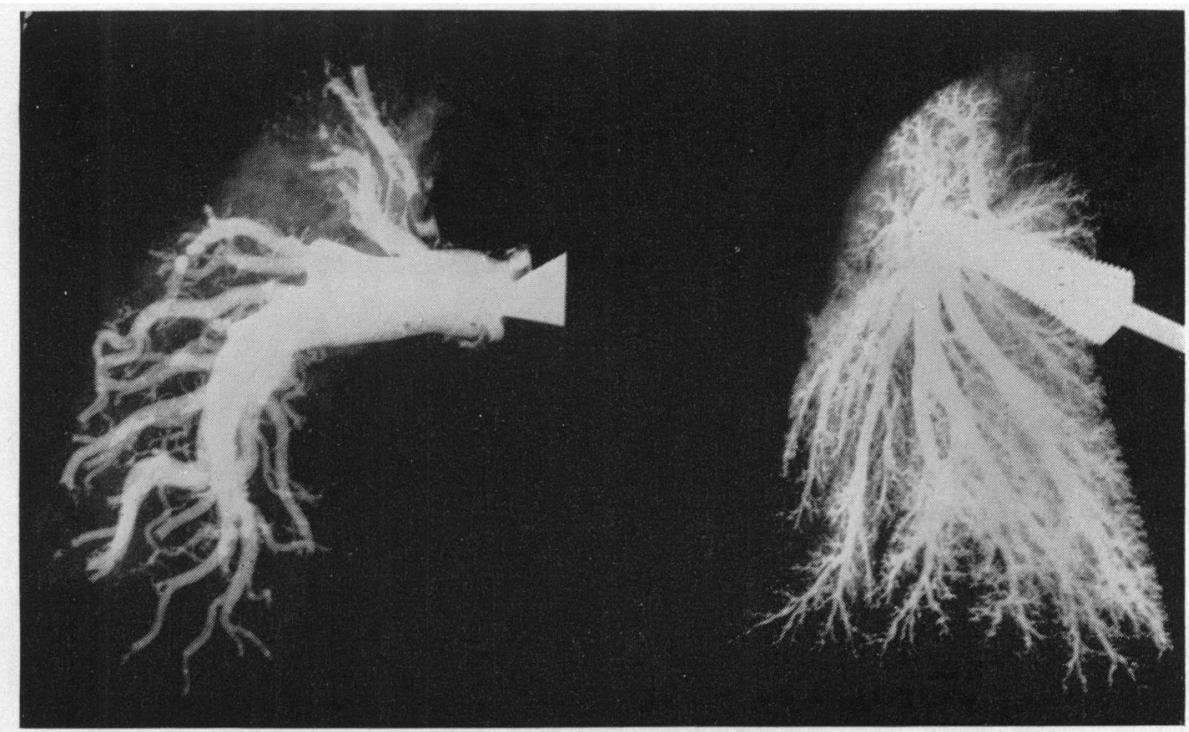

FIG. 5.-Post-mortem pulmonary arteriogram (left) of the patient (Case K.H.) whose plain X-ray appears in Fig. 4, beside a normal lung similarly treated by injection of barium sulphate into pulmonary artery and its branches (right). Note the failure of the contrast medium to fill peripheral branches of the pulmonary artery of Case K.H. Upper and lower zones are equally affected, and large arterial trunks are tortuous. 


\section{Cardiac Catheterization and Further Laboratory Tests}

Cardiac catheterization in all cases showed severe pulmonary hypertension but no evidence of a shunt. In no case was a wedge pressure obtained. This might have been due to the sudden diminution in calibre of the pulmonary vessels as shown in Fig. 5 or to a transmission of the pulmonary artery pressure to the catheter tip by abnormal channels that are discussed below.

With a view to trying the effect of a lysergic acid derivative (UML 491)* on the pulmonary vascular resistance, as suggested by Halmagyi (1959), a second cardiac catheterization was performed in one case six months later. The effect of UML 491 was disappointing, and the second catheterization revealed the rapid progression of the disease during the six months' interval, as evidenced by the rise in right ventricular and pulmonary arterial systolic pressures, and the increase in the arterio-venous oxygen difference. A notable feature was the fall in pulmonary artery pressure after the inhalation of pure oxygen (Table I).

TABLE I

Hemodynamic Data in a Patient with Primary Pulmonary Hypertension

\begin{tabular}{|c|c|c|c|c|c|c|}
\hline \multirow{2}{*}{\multicolumn{2}{|c|}{ Date }} & \multicolumn{4}{|c|}{ Pressures $(\mathrm{mm} . \mathbf{H g})$} & \multirow[b]{2}{*}{$\begin{array}{c}\text { Arterio-venous } \\
\text { oxygen } \\
\text { difference } \\
\text { (volumes \%) }\end{array}$} \\
\hline & & $\begin{array}{l}\text { Pulmonary } \\
\text { artery }\end{array}$ & $\begin{array}{c}\text { Pulmonary } \\
\text { artery after } \\
\text { oxygen } \\
\text { inhalation }\end{array}$ & $\underset{\text { ventricle }}{\text { Right }}$ & $\begin{array}{l}\text { Brachial } \\
\text { artery }\end{array}$ & \\
\hline $7 / 7 / 59$ & .. & $80 / 40$ & - & $80 / 7$ & $108 / 67$ & $4 \cdot 6$ \\
\hline $5 / 1 / 60$ &. & $130 / 63$ & $103 / 51$ & $114 / 4$ & $90 / 71$ & $6 \cdot 4$ \\
\hline
\end{tabular}

The subject of the effect of drugs on a raised pulmonary vascular resistance has been well reviewed by Halmagyi (1959). The use of drugs has been encouraged by the paucity of structural vascular change occasionally observed in cases with very high resistance (De Navasquez et al., 1940; Dresdale et al., 1954). Among the drugs that have been used, priscoline (Dresdale et al., 1954), acetyl choline (Wood and Besterman, 1956; Shepherd et al., 1959), and reserpine (Halmagyi et al., 1957) were the most encouraging.

Numbers of other drugs have been tried with varying degrees of success, but their associated systemic effects present difficulties. The lysergic acid derivative mentioned above (UML 491) was tested because of its action as a serotonin antagonist, and of the powerful pulmonary vaso-constrictive effect that serotonin has been shown to have experimentally (Page, 1958).

UML 491 was injected through a catheter with its tip in the pulmonary artery in divided doses of 5,10 , and 10 micrograms up to a total of 25 micrograms on two occasions in different patients without any fall in pulmonary artery pressure. In one case there was a slight rise in pressure, and such a finding was also noted experimentally by Halmagyi (1960).

Attempts were made to determine whether the illness was the result of an auto-immune process affecting particularly lung vessels. The sedimentation rate in two of the patients was normal. In one of these patients a trypsinogenized red cell test and an indirect Coombs test were negative. This patient, however, certain members of whose family had suffered a similar early minor illness, had a slight increase in the serum $\beta$ globulin. Wade and Ball (1957) obtained a positive differential agglutination test in two of their ten patients with primary pulmonary hypertension. 


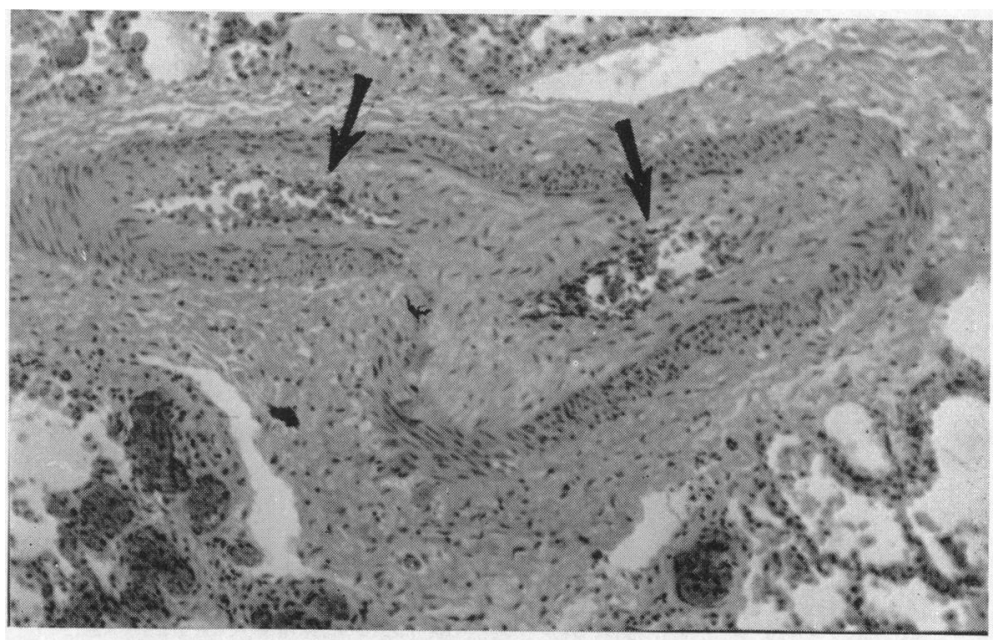

FIG. 6.-Concentric intimal hyperplasia (indicated by arrows) in a mediumsized pulmonary artery, as seen only in occasional vessels (Hæmatoxylin and eosin $\times 80$ ).

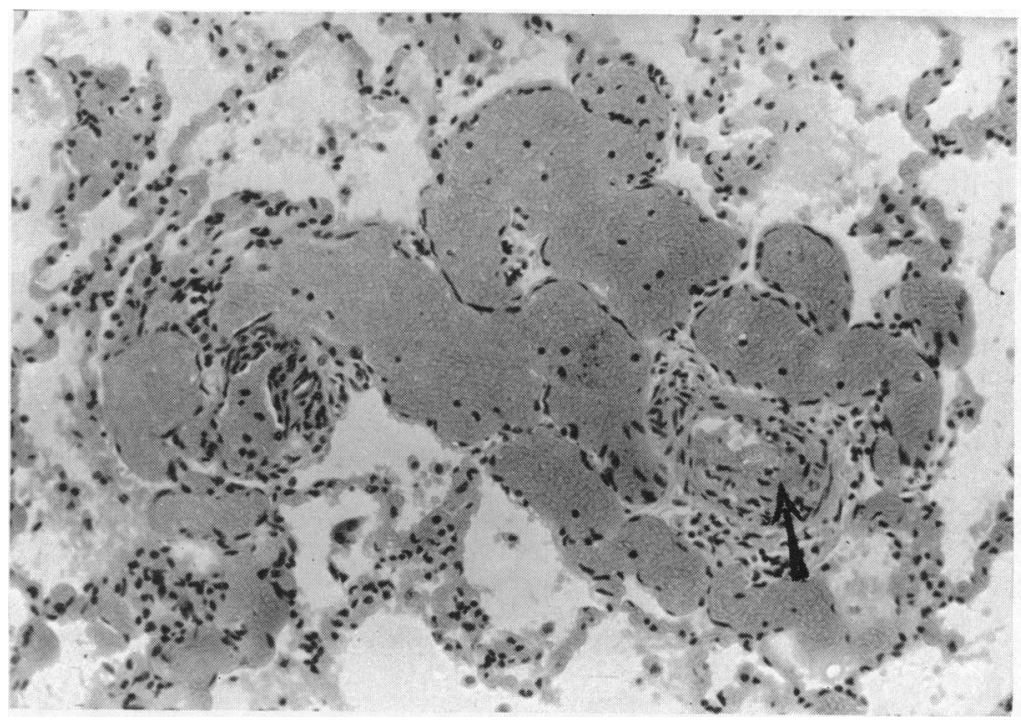

Fig. 7.-Abnormal blood vessel formation occurring in relation to a partially occluded pulmonary arteriole (arrow). (Hæmatoxylin and eosin $\times 170$.)

\section{TREATMENT}

In addition to the administration of anti-serotonin substances, steroids, anticoagulants, and reserpine were likewise without beneficial effect in one patient. The complete failure of prednisone in this patient, in doses sufficient to produce a marked increase in weight was disappointing. 


\section{Pathological Findings}

Autopsy in three cases confirmed the absence of any large single communication between the two circulations. Right ventricular hypertrophy, sometimes with dilatation, was always present and there was usually some degree of dilatation of the tricuspid valve ring. Right atrial enlargement was present but was not much and there were changes in the liver due to venous congestion.

The Lungs. Thrombosis of the pulmonary arteries of recent origin and in various stages of organization was the outstanding feature in all and in two the thrombosis had developed mainly in arteries damaged by arteritis or by high pressure. There was uniform musculo-elastic hypertrophy in the larger arteries and a comparable increase in muscle tissue in the smaller branches, even to those of capillary size which, in children of this age group, do not normally contain muscular tissue. In contrast, concentric intimal hyperplasia was found only occasionally (Wade and Ball, 1957) in small and medium sized vessels, and it is not unlikely that this fibrous thickening was also secondary to thrombosis, as the much commoner eccentrically placed mounds of intimal fibrous tissue were judged to be (Fig. 6). This interpretation agrees with the findings in certain of the cases described by Berthrong and Cochran (1955). Rarely the lumen of small arteries was narrowed by an inner hypertrophied layer of longitudinally arranged smooth fibres.

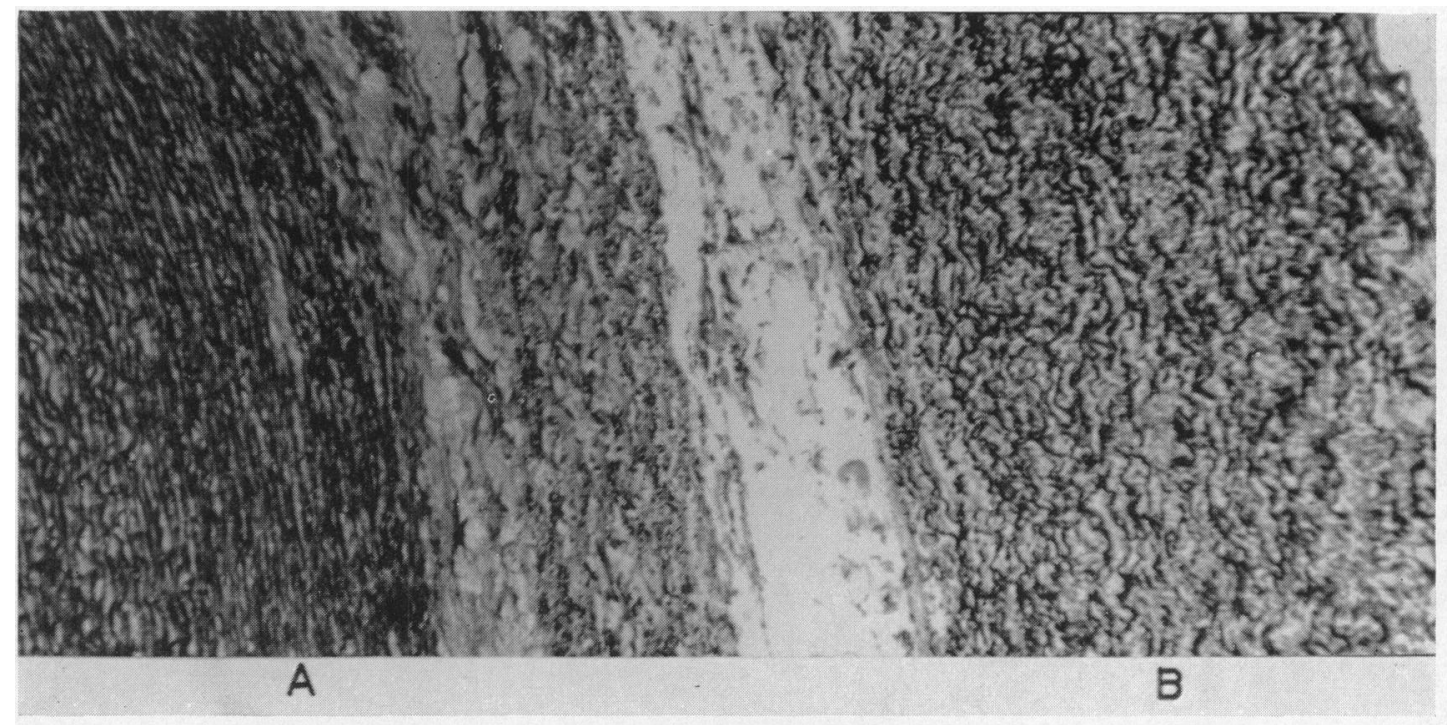

Fig. 8.-Contiguous aorta and pulmonary trunk from a sixteen-months-old male child with normal cardiovascular system. On the left is the aorta (A). On the right (B) can be seen the atrophic changes that have already occurred in the elastic tissue of the pulmonary trunk. (Combined elastic and connective tissue stain $\times 80$.)

Unusual vessel formations, previously described by Heath (1959), were seen. These were clusters of thin-walled capillaries frequently occurring in relation to a thrombosed vessel (Fig. 7). The studies of Wagenvoort (1959) suggested that such vessels seen in cases of pulmonary hypertension were not bronchial vessel anastomoses. This would disagree with Brinton (1950), who suggested on embryological grounds that it might be the case. Nor would it be supported by our cardiac catheterization studies where pulmonary arterial pressures were higher than systemic. Taylor (1960) suggested that these vessels may account for the inability to obtain reliable indirect left atrial pressures when the catheter appeared to be in a wedged position in the pulmonary arterial tree. Pulmonary arterial pressure may thus be transmitted to the catheter tip and so vitiate the true wedge readings. 


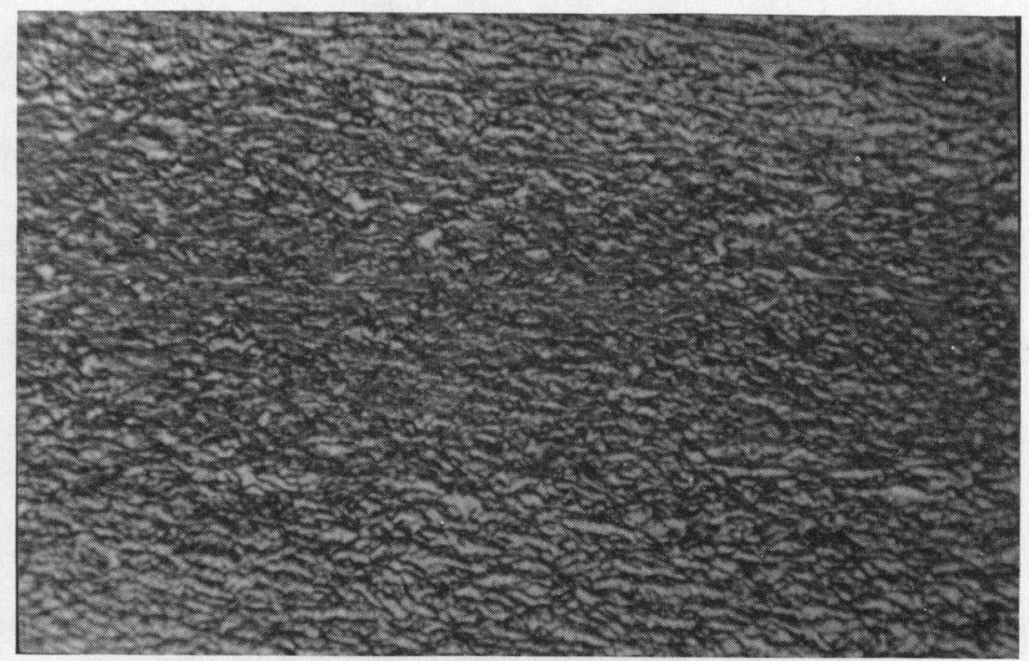

FIG. 9 (A).-Transversely cut section of pulmonary trunk taken at autopsy. (Combined elastic and connective tissue stain $\times 80$.) Four-year-old girl who suffered from primary pulmonary hypertension. Dense slightly irregularly elastic tissue, with minimal atrophic change.

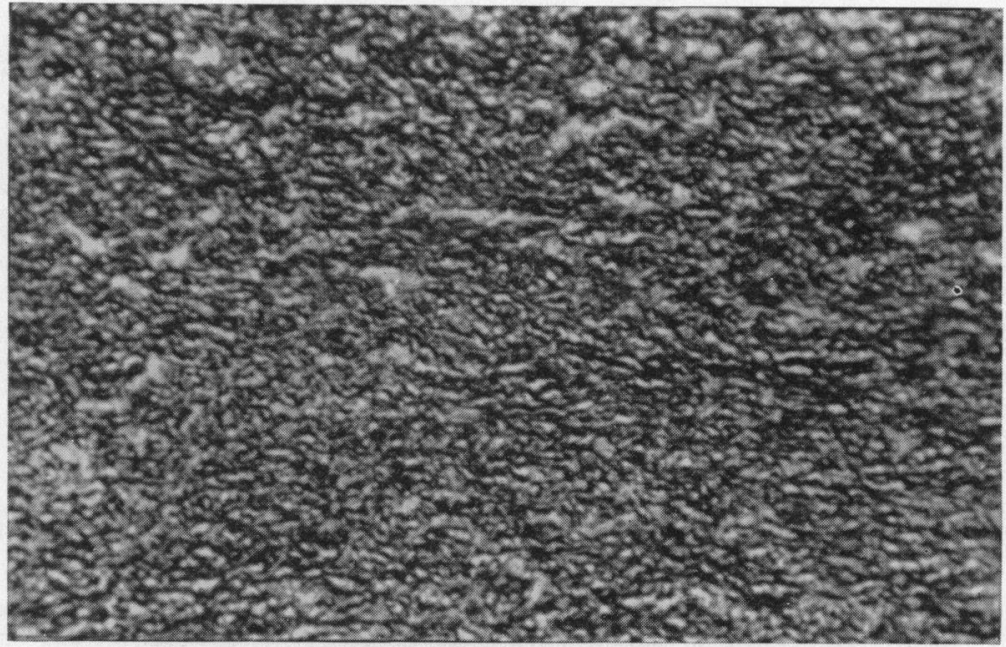

Fig. 9 (B).-Transversely cut section of pulmonary trunk taken at autopsy. (Combined elastic and connective tissue stain $\times 80$.) Six-year-old girl who had suffered from primary pulmonary hypertension. Dense elastic tissue is quite irregular.

A special study was made of the main pulmonary trunk following the suggestion by Heath et al. (1959), and Heath $(1959,1960)$ that the congenital or acquired nature of pulmonary hypertension in any given patient could be determined by a careful examination of the configuration of the elastic tissue of the media. The pulmonary vascular resistance gradually diminishes after birth, producing a fall in pressure within the pulmonary trunk. There are consequently atrophic changes of the elastic tissue within its wall and a gradual change occurs from the fotal pattern, which is similar to that found in the fœtal or adult aorta, in which elastic fibres are parallel and tightly packed. While 
the aorta retains this pattern into adult life, the pulmonary trunk undergoes simple atrophy and changes to a pattern in which the fibres become broken up, develop rounded enlargements at the ends of the fragments, and collagen fills the intervening spaces (Fig. 8). In our sections there was a great increase in elastic tissue compared with that usually seen in the pulmonary arteries of children who had normal pulmonary circulations (Brenner, 1935; Rosen et al., 1957). There was, however, some discontinuity and the fibres were not as parallel nor as tightly packed as in the normal new born infant. Furthermore, the younger the patient the more closely did the pattern resemble the fotal one (Fig. 9A, 9B, 9C, 9D). One would have thought that, if a clear differentiation between adult and fœtal patterns were possible, the adult pattern might have been attained and retained after three years of normal pulmonary artery pressure, if the findings of Heath et al. (1959) could be applied to these unusual patients.

\section{Discussion}

In considering the ætiology, particularly of the rapidly progressive cases, one can exclude most of the causes of obliterative pulmonary hypertension usually found in adults. Three possibilities remain to be considered. The first of these is the retention of the thick muscular type of fœtal vessels with a high resistance to flow. The second is a thrombotic state initiated by small emboli from peripheral venous thrombosis lodging in the lungs; and the third is an allergic arteritis affecting only lung vessels, with subsequent thrombosis and organization.

In any of these, it is difficult at autopsy to know how much of the pulmonary vascular resistance was contributed to by vasoconstriction, whether neurogenic or hormonal. Halmagyi (1959) pointed out that this factor will vary from case to case and this concept will support the generally accepted view that the cases in this group are ætiologically different. On the other hand Dresdale et al. (1951, 1954) believed that the resistance was mainly functional and, in support of this, pointed to the beneficial effects of priscoline.

After consideration of clinical, electrocardiographic, and pathological material, a congenital basis can reasonably be excluded, unless one accepts the contention of Evans et al. (1957) that congenital defects in the media of small muscular arteries cause an abnormal intimal hyperplasia. There was a clear period of health before the sudden onset of symptoms varying from four months to one year before death. The electrocardiogram in one patient supported the possibility of rapidly developing ventricular hypertrophy of recent onset, but only one cardiogram was available in each of the other two fatal cases. Although the arterial vessels were rather like those seen in fœtal lungs, it cannot be said that the muscular hypertrophy had been present since fotal life to support the suggestion of a congenital ætiology. Furthermore, the elastica of the pulmonary trunk did not have a distinct fætal pattern. Harrison (1960), having examined sections from two of our cases (Fig. 9A and 9B), believed without hesitation that this was an acquired disease. Heath (1960), who also kindly examined the section in Fig. 9C was uncertain and said that this case was one of the only two in which he had been unable to decide the congenital or acquired nature of the disease by this examination.

There was no evidence at autopsy on macroscopic examination in favour of peripheral vein thrombosis or inflammation. It could be argued that microscopic peripheral thrombi might pass to the lungs and lodge there where larger thrombi may develop (Wood, 1959). There was, however, a suggestion that the illness was the result of an auto-immune process from the preceding history in two of the three patients who died. It is true that there was no supporting laboratory evidence for an auto-immune reaction, but it could have been that this process was by then quiescent although it had left a permanent structural change in the vessels. Mackay (1959) of the Walter and Eliza Hall Institute in Melbourne had no experience of an auto-immune process affecting the lungs alone and the sections in no way resembled those of Read (1958) who produced a pneumono-toxic pneumonia in rats by instillation of rabbit anti-rat lung serum into the respiratory passages of the rat. Arteritis was not a prominent feature of his sections.

Although the four cases discussed in this paper were not exactly similar in clinical or pathological 


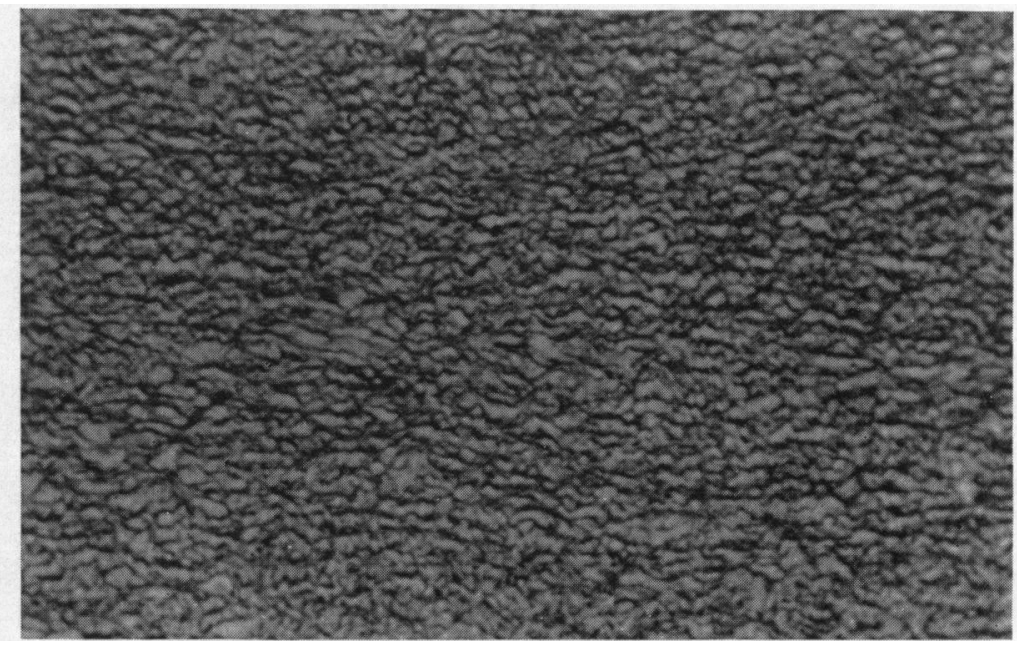

FIG. 9 (C).-Transversely cut section of pulmonary trunk taken at autopsy. (Combined elastic and connective tissue stain $\times 80$.) Nine-year-old boy who had suffered from primary pulmonary hypertension. The elastic tissue, though not of the fotal type, is denser and more tightly packed than that which occurs in a normal pulmonary trunk at similar ages.

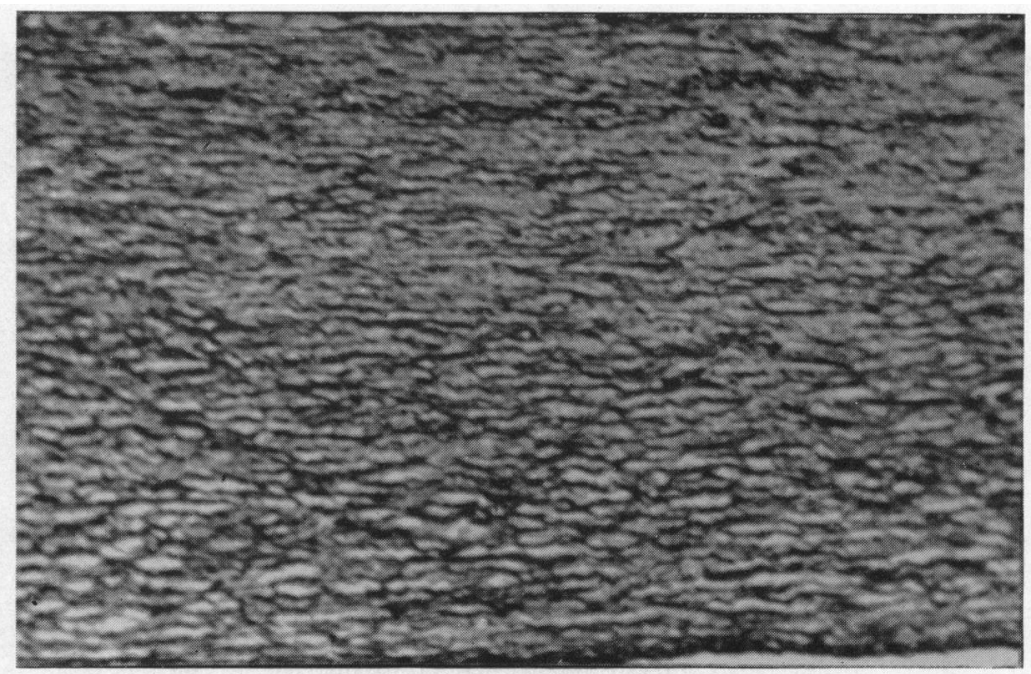

FIG. 9 (D).-Transversely cut section of pulmonary trunk taken at autopsy. (Combined elastic and connective tissue stain $\times 80$.) Ten-year-old boy who had died from tetanus, showing normal atrophic changes in the elastic tissue of the pulmonary trunk.

detail, at least they had two points in common: they represented acquired diseases and had as their dominating feature thromboses in pulmonary vessels. Whether the fact that this disease is usually observed in adults supports the theory of an auto-immune process remains to be seen. It is hoped that these cases described in children may offer a clue in a hitherto difficult problem. 


\section{SUMMARY}

Four cases of primary pulmonary hypertension are described in children, aged four to nine years. Clinical, electrocardiographic, radiographic, and cardiac catheterization findings are similar in most respects to the cases usually described in adults.

The group is distinct from another group of infants who died with right ventricular hypertrophy and right ventricular failure that remained unexplained after autopsy.

A lysergic acid derivative with anti-serotonin properties (UML 491) in modest dosage failed to reduce the pulmonary vascular resistance in two cases.

Clinical and ancillary evidence suggested that the disease was an acquired one. Examination of the main trunks of the pulmonary arteries was carried out in the three fatal cases, but unequivocal support for the acquired nature of the disease was not obtained. Thrombosis in small arteries was the dominating feature in the lungs.

No certain cause for the pathological changes was discovered, nor was it suggested that the cause was the same in each case.

Three of the four cases presented for examination within a period of two months.

We should like to express our thanks to the following: Professor Lorimer Dods, Honorary Director of the Children's Medical Research Foundation for his advice and criticism; Dr. W. A. Seldon, cardiologist to St. Vincent's Hospital, Sydney, for extending every facility to us to observe one of the patients; Mr. H. J. Mitchell, chief medical technologist, Institute of Pathology, Royal Alexandra Hospital for Children, Sydney; Mr. C. Noble, clinical photographer to the Royal Alexandra Hospital for Children, Sydney; Mrs. J. V. Roberts, secretary to the Children's Medical Research Foundation; and to the medical and technical staff of the hospital who made the care and observation of the patients possible.

\section{REFERENCES}

Berthrong, M., and Cochran, T. H. (1955). Bull. Johns Hopk. Hosp., 97, 69.

Brenner, O. (1935). Arch. intern. Med., 56, 211.

Brinton, W. D. (1950). Brit. Heart. J., 12, 305.

Chapman, D. W., Abbott, J. P., and Latson, J. (1957). Circulation, 15, 35.

Coleman, P. N., Edmunds, A. W. B., and Tregillus, J. (1959). Brit. Heart J., 21, 81.

Cross, K. R., and Kobayshi, C. K. (1947). Amer. J. clin. Path., 17, 155.

De Navasquez, S., Forbes, J. R., and Holling, H. E. (1940). Brit. Heart J., 2, 177.

Davies, L. G., Goodwin, J. F., Steiner, R. E., and Van Leuven, B. D. (1953). Brit. Heart J., $15,393$.

Doyle, A. E., Goodwin, J. F., Harrison, C. V., and Steiner, R. E. (1957). Brit. Heart J., 19, 353.

Dresdale, D. T., Michtom, R. J., and Schultz, M. (1954). Bull. N. Y. Acad. Med., 30, 195.

$\longrightarrow$, Schultz, M., and Michtom, R. J. (1951). Amer. J. Med., 11, 686.

Evans, W., Short, D. S., and Bedford, D. E. (1957). Brit. Heart J., 19, 93.

Fleming, H. A. (1960). Aust. Ann. Med., 9, 18.

Halmagyi, D. F. J., Felkai, B., Czipott, Z., and Kovacs, G. (1957). Brit. Heart. J., 19, 375.

- (1959). J. chron. Dis., 9, 525.

- (1959). Personal communication.

Harrison, C. V. (1960). Personal communication.

Heath, D., DuShane, J. W., Wood, E. H., and Edwards, J. E. (1959). J. Path. Bact., 77, 443.

- (1959). Pulmonary Circulation. Grune \& Stratton, New York, 1959.

- (1960). Personal communication.

Mackay, I. (1959). Personal communication.

Okuyama, K. (1958). Padiatria Universitatis Tokyo, 2, 67.

Page, I. H. (1958). Physiol. Rev., 38, 277.

Read, J. (1958). J. Path. Bact., 76, 403.

Rosen, L., Bowden, D. H., and Uchida, I. (1957). Arch. Path., 63, 316.

Taylor, M. G. (1960). Personal communication.

Wade, G., and Ball, J. (1957). Quart. J. Med., 26, 83.

Wagenvoort, C. A. (1959). J. Path. Bact., 78, 503.

Wood, P. (1956). Diseases of the Heart and Circulation. London, Eyre \& Spottiswoode.

, and Besterman, E. M. M. (1956). Brit. med. J., 1, 113.

- (1959). Personal communication. 